\title{
PESQUISA-AÇÃO COMO ESTRATÉGIA PARA PREVENÇÃO LESÃO POR PRESSÃO CALCÂNEA EM PACIENTES COM QUEIMADURAS
}

\author{
Fernanda Lobo Tavares \\ Instituto Jurídico de Efetivação e Cidadania - Avante Social \\ fernanda.lobotavares@yahoo.com.br \\ Cynthia Carolina Duarte Andrade \\ FHEMIG \\ cynthiacarolinaduarteandrade@gmail.com \\ Izabela Figueiredo de Sousa Honorato \\ HJXXIII / FHEMIG \\ belafigues79@gmail.com
}

\section{RESUMO}

OBJETIVO: Comparar a prevalência de LP calcâneas em pacientes internados em UTI de um Centro de Referência de Queimados em MG antes e após a ação educativa. MÉTODO: Estudo descritivo com abordagem quantiqualitativo desenvolvido por meio de pesquisa-ação baseada nas quatro etapas dinâmicas de planejamento descritas por Thiollent (diagnóstico situacional, planejamento, implementação e avaliação). Foram realizadas oficinas de sensibilização e pactuação de metas. Previamente a ação educativa (julho de 20I9) e três meses após a ação (agosto, setembro e outubro de 2019) foram calculadas as prevalências pontuais mensais. RESULTADOS: A ação educativa proporcionou a redução significativa da prevalência de LP em calcâneos de pacientes com queimaduras em 85,7I\% (77,7\%- II,I\%) em 3 meses. Durante o período da pesquisa foram acompanhados 3 I pacientes e I3 LP, sendo a maioria classificada como lesões tissulares profundas (38,4\%) e inclassificáveis (I5,3\%). Dentre essas I3 LP 46,3\% são de espessura parcial e 53,7\% são de espessura total. CONCLUSÃO: A metodologia pesquisa-ação foi efetiva para reduzir a prevalência de LP calcâneas em pacientes queimados.

PALAVRAS-CHAVE: Lesão por pressão; Calcâneo; Educação Continuada. 